\title{
PELATIHAN PENULISAN KREATIF TERSTRUKTUR
}

\author{
Lalu Jaswadi Putera ${ }^{1^{*}}$, Muh. Khairussibyan ${ }^{2}$ \\ ${ }^{1}$ Pendidikan Bahasa Inggris, Universitas Mataram, elputra.unram@gmail.com \\ 2Pendidikan Bahasa Indonesia, Universitas Mataram, sibyan_hair@yahoo.com
}

\begin{abstract}
ABSTRAK
Abstrak: Pelatihan Penulisan Kreatif Terstruktur di MA Raudhatusshibyan NW Belencong ini bertujuan untuk: 1) mengakrabkan peserta didik dengan budaya literasi; 2) membelajarkan peserta didik agar memiliki keterampilan literasikhususnya keterampilan menulis terstruktur dalam bahasa Indonesia; 3) memotivasi peserta didik untuk menulis kreatif dan terstruktur dalam kehidupan sehari-hari; 4) membantu tugas para guru dalam membelajarkan keterampilan literasi. Mitra kegiatan pengabdian masyarakat ini adalah pihak yayasan dan pengurus MA Raudhatusshibyan. Pelaksanaan pengabdian ini diharapkan dapat meningkatkan keterampilan peserta khususnya dalam teknik penulisan kreatif terstruktur Bahasa Indonesia dan meningkatkan pemahaman pelajar terhadap nilai-nilai budaya literasi.

Kata Kunci: literasi, penulisan kreatif, MA Raudhatusshibyan

Abstract: This community service themed structured-creative writing training at $M A$ Raudhatusshibyan NW Belencong aims to: 1) raise awareness of the importance of the literate culture among students; 2) train students to become more literate and skillful especially in structured-creative writing in Indonesian language; 3) enthuse students to eagerly write structured-creative writing in their daily life; and 4) help teachers in improving the students' literacy skill. Our partners in this community service are the foundation and the administrators of MA Raudhatusshibyan NW Belencong Gunung Sari. It is hoped that this community service can improve the students' literacy skill especially in structured-creative writing in Indonesian language as well as increase the students' understanding of the values of literacy.
\end{abstract}

Keywords: literacy, creative writing, MA Raudhatusshibyan

Riwayat Artikel: Diterima: 03 Desember 2017, Disetujui: 29 Januari 2018 


\section{A. PENDAHULUAN}

Keterampilan literasi (membaca dan menulis) sangat penting dalam pemerolehan dan pengembangan pengetahuan baik pengetahuan tradisional, pengetahuan keagamaan, maupun pengetahun saintifik. Ilmu pengetahuan hanya mungkin berkembang dalam masyarakat yang memiliki budaya literasi (kelisanan dan keberaksaraan) yang baik. Begitu pun warisan pengetahuan dari masa lalu tidak akan sampai kepada generasi saat ini tanpa adanya tradisi kelisanan dan keberaksaraan yang baik.

Berbeda dengan tradisi dan keterampilan kelisanan (orality), tradisi dan keterampilan keberaksaraan (literacy), menghasilkan suatu artefak, dalam hal ini catatan atau cetak, yang bersifat relatif permanen yang bisa dibaca atau ditelaah di waktu dan tempat yang berbeda-beda [1]. Di samping itu, salah satu ciri tradisi kelisanan adalah kurang mampu mengungkapkan suatu pikiran secara asbtrak dan sistematis. Dengan logika dan bentuk abstrak, penguraian secara formal dan sistematis hanya dapat berkembang dengan hadirnya keberaksaraan [2].

Di samping itu, budaya literasi mendidik penggunanya untuk menghargai hasil pemikiran orang lain berupa ide, prakarsa, konsep, dan sebagainya. Dalam tradisi kelisanan, konsep atau pemikiran yang disampaikan oleh penutur cenderung tak terstruktur dan terikat pada konteks penuturannya. Berbeda dari itu, budaya literasi mensyaratkan penyusunan teks yang terstruktur agar mudah dipahami dan bisa mencapai sasaran pembaca yang beraneka ragam.

Tradisi kelisanan dan keberaksaraan yang baik memiliki peran yang tak kalah penting dalam menciptakan individu-individu atau kelompok masyarakat bermoral tinggi dan berpikiran maju. Bangsa yang maju dan bermoral tinggi lahir dari masyarakat yang di dalamnya berkembang budaya literasi yang mumpuni. Negaranegara dengan masyarakat yang memiliki tingkat literasi yang tinggi terbukti mampu meraih podium tertinggi pada level-level internasional. Singapura, contohnya, mampu melesat menjadi negara dengan tingkat pendidikan nomor 1 di ASEAN dan nomor 9 di dunia. Demikian pula negara seperti Finlandia mampu menduduki peringkat 1 dalam indeks tingkat literasi dunia. Sementara Indonesia untuk sementara harus puas pada posisi 60 dari 61 negara dalam kriteria melekliterasi ini [3].

Bila kita melihat kenyataan yang ada, Indonesia sebagai bangsa dengan kultur kelisanan yang kuat menghadapi tantangan yang tidak mudah dalam pembudayaan keterampilan literasi di kalangan generasi muda. Pembudayaan keterampilan literasi menjadi semakin berat ketika memasuki era informasi digital seperti saat ini [4].

Era komunikasi digital mengubah cara orang berpikir dan bertindak. Pola komunikasi menjadi lebih bervariasi setelah munculnya media-media komunikasi digital. Media komunikasi digital seperti seperti facebook, twitter, whatsapp, line, instagram, dan sebagainya yang menyediakan fitur-fitur baru tidak hanya mengubah pola komunikasi konvensional, tetapi juga menggeser cara orang merepresentasikan dirinya dalam tindak komunikasi. Para pengguna media sosial bisa berkomunikasi dengan lisan, tulisan, dan gambar sekaligus. Hal ini secara langsung mengakrabkan para pengguna layanan tersebut terhadap aktivitas literasi.

Akan tetapi, literasi digital tersebut tidak sertamerta menjadikan para pengguna menjadi terampil menulis terstruktur. Hal ini disebabkan, literasi digital masih didominasi oleh tradisi kelisanan dan tradisi menonton dan mendengar. Dengan demikian, tantangan para pendidik dan dosen dalam mengajarkan keterampilan menulis menjadi tidak berkurang di era informasi digital ini.

Fungsi utama pendidikan di tiap tingkat adalah untuk menyediakan pelatihan cara-cara berpikir mendasar [5]. Penulisan sebagai salah satu bentuk pelatihan cara berpikir sekaligus bentuk pengungkapan hasil pemikiran merupakan kegiatan yang 
perlu diterapkan pada hampir semua jenjang pendidikan mulai tingkat dasar, menengah, dan tinggi.

Sekolah menengah atas merupakan fase yang baik sekali untuk melatih peserta didik mengasah keterampilan menulis mereka sebab pada fase ini mereka sudah menguasai pengetahuan-pengetahuan dasar tentang diri dan dunianya sekaligus juga merupakan fase persiapan menuju jenjang pendidikan tinggi. Di perguruan tinggi, peserta didik diharapkan sudah memiliki keterampilan dasar penulisan agar bisa menyelesaikan tugas-tugas perkuliahan dan aktivitas penulisan lainnya.

Pembudayaan literasi khususnya keterampilan menulis ini semakin penting segera diperkuat di kalangan generasi muda mengingat Indonesia sudah memasuki Masyarakat Ekonomi Asean (MEA). MEA menipiskan batas-batas negara yang memungkinkan terjadinya interaksi lebih intensif dan meningkatkan kompetisi antar perorangan dan antar lembaga negara-negara Asean. Salah satu keterampilan penting yang mesti dimiliki oleh peserta didik dalam MEA adalah keterampilan komunikasi lisan dan tulisan yang terstruktur.

Selain karena kurangnya bahan literasi yang tersedia, di antara kemungkinan penyebab masalah tersebut adalah kualitas dan kuantitas pembelajaran menulis yang tidak intensif. Oleh karena itu, pelatihan dasar penulisan penting diintensifkan di sekolah. Kegiatan ini di samping penting bagi peserta didik, penting juga bagi para guru dan dosen sebab akan membantu tugas mereka. Inilah sebabnya, masalah ini diangkat dalam pengabdian masyarakat ini.

\section{B. METODE PELAKSANAAN}

Kegiatan pengabdian masyarakat ini berupa pelatihan menulis terstruktur dalam Bahasa Indonesia. Adapun materi yang disajikan adalah materi teknik penulis kreatif terstruktur dalam Bahasa Indonesia yang disampaikan oleh Lalu Jaswadi Putera, M.Pd. dan Muh. Khairussibyan, M.A. Pemberian materi tersebut disertai dengan pembimbingan penulisan terstruktur. Adapun langkah-langkah yang dijalankan dalam pelatihan ini adalah sebagai berikut.

1. Pemberian materi tentang pentingnya memiliki keterampilan menulis.

2. Pemberian materi tentang tema-tema yang bisa diangkat dalam tulisan.

3. Pemberian materi tentang cara mendapatkan ide dan bahan penulisan.

4. Pemberian materi tentang cara menentukan sudut pandang yang baik dalam penulisan.

5. Pemberian reward berupa buku bacaan kepada peserta yang menulis dengan sudut pandang terbaik.

6. Pemberian materi tentang pentingnya menyusun kerangka karangan dan cara penyusunannya.

7. Para peserta diminta menulis sesuai dengan kerangka karangan yang telah ditentukan.

8. Pemberian reward berupabuku bacaan kepada empat peserta dengan tulisan terkreatif dan struktur terbaik.

\section{HASIL DAN PEMBAHASAN}

\section{Pelaksanaan Kegiatan}

Secara keseluruhan, pelaksanaan pelatihan berlangsung lancar dan sesuai rencana. Pihak-pihak terkait terutama lembaga sekolah sangat mendukung terlaksananya kegiatan pelatihan. Hal ini ditunjukkan dengan disediakannya ruangan, proyektor, dan menggalang partisipasi siswa untuk mengikuti pelatihan.

Peserta yang hadir berjumlah 21 orang Terdiri dari 18 siswa perempuan dan 3 siswa laki-laki kelas XI IPS MA Raudlatusshibyan NW Belencong. Sebelum mengikuti pelatihan, para siswa diberikan alat-alat tulis berupa buku dan pulpen. 
Kepala sekolah membuka acara pelatihan dengan memberikan nasehat agar para peserta mengikuti pelatihan dengan baik. Setelah acara pembukaan, peserta diberikan materi pertama tentang penulisan kreatif. Pada bagian ini, pemateri memberikan materi terkait alasan filosofis dan teknis tentang pentingnya memiliki skill literasi yang mencukupi. Pemateri memberikan contoh-contoh tentang manfaat penguasaan skill literasi dalam mencapai tujuan belajar, tujuan hidup, dan dalam menjalani kehidupan sehari-hari.

Selama pemberian materi ini, siswa diajak untuk latihan mengungkapkan pikiran dan sudut pandang atas fenomena sehari-hari dalam bahasa tulis. Pada bagian ini, peserta dilatih untuk menentukan sudut pandang dalam menulis. Siswa diminta menulis satu topik yang sama dengan sudut pandang yang berbeda-beda. Peserta yang menulis dengan sudut pandang terbaik diberikan reward berupa sebuah buku. Tidak sedikit dosen di perguruan tinggi mengeluh tentang kemampuan mahasiswa baru dalam menyelesaikan tugas-tugas perkuliahan. Mereka mempertanyakan pembelajaran bahasa Indonesia di sekolah menengah. Dalam kurikulum mata pelajaran Bahasa Indonesia sesungguhnya terdapat materi-materi pembelajaran yang bertujuan memberikan penguasaan kompetensi penulisan bagi peserta didik. Kenyataannya, rata-rata peserta didik tidak menguasai kompetensi yang seharusnya dimiliki dalam bidang penulisan.

Selanjutnya pemateri melatih peserta untuk membuat outline tulisan yang terstruktur. Hal ini dilakukan sebab outline tulisan yang terstruktur akan membantu peserta untuk melaksanakan tugas selanjutnya yaitu mengembangkan outline menjadi rangkaian paragraf yang baik sekaligus menarik.

Kegiatan terakhir adalah menilai dan menentukan tulisan terbaik diantara seluruh tulisan peserta. Keempat peserta terpilih didaulat untuk membaca tulisan terbaik karya sendiri di hadapan seluruh peserta. Empat peserta dengan tulisan terkreatif dan struktur terbaik mendapat reward berupa buku bacaan karya penulis-penulis nasional kenamaan. Penghargaan ini dimaksudkan untuk memacu semangat menulis sekaligus meningkatkan budaya literasi di kalangan generasi muda.

\section{Faktor Penghambat dan Faktor Pendukung}

Selama kegiatan, tidak ditemukan hambatan yang berarti. Acara pelatihan berlangsung lancar sesuai dengan rencana. Hal ini terutama karena pihak sekolah dan peserta pelatihan cukup antusias mendukung terlaksananya pelatihan.

Faktor yang mendukung terlaksananya kegiatan pelatihan ini adalah kooperatifnya pihak MA Raudhatusshibyan dan baiknya pemahaman peserta tentang pentingnya pelaksanaan pelatihan ini. Pihak sekolah bahkan menyarankan kepada tim penulis untuk menindaklanjuti kegiatan ini dengan kegiatan selanjutnya yang relevan.

\section{SIMPULAN DAN SARAN}

Kegiatan Pengabdian Masyarakat Pelatihan Penulisan Kreatif Terstruktur ini dapat disimpulkan sebagai berikut.

1. Kegiatan dilangsungkan pada hari Sabtu tanggal 21 Oktober 2017, bertempat di MA Raudlatusshibyan NW Belencong. Peserta kegiatan adalah siswa kelas XI IPS MA Raudlatusshibyan NW Belencong.

2. Tahapan kegiatan berlangsung sesuai dengan rencana pelaksanaan. Para peserta pelatihan mengikuti pelatihan dengan antusias.

3. Materi yang disampaikan dalam pelatihan ini adalah materi-materi terkait pengembangan minat dan keterampilan peserta dalam penulisan terstruktur. 
4. Materi pelatihan disampaikan dengan ceramah, diskusi, dan latihan dengan menggunakan instrumen pembelajaran yang telah disiapkan.

5. Evaluasi atas proses dan hasil pelatihan menunjukkan bahwa para peserta mendapatkan pemahaman yang baik tentang keterampilan menulis setelah mengikuti pelatihan ini.

\section{UCAPAN TERIMA KASIH}

Tim penulis mengucapkan terima kasih kepada pihak Universitas Mataram terutama Bapak Rektor Universitas Mataram, Pembantu Rektor I Universitas Mataram, Ketua UPT MKU Universitas Mataram, dan ketua LPPM Universitas Mataram yang telah memberikan kemudahan dalam pengurusan perizinan dan penugasan, kepada pihak MA Raudlatusshibyan NW Belencong atas dukungan berupa sambutan dan penyediaan ruangan dan peserta.

\section{DAFTAR PUSTAKA}

[1] Ong WJ, Hartley J, Orality and Literacy, Routledge, London, h. 1-6, 2002.

[2] Sunarti, Sastri, Kelisanan dan Keberaksaraan dalam Surat Kabar Terbitan Awal di Minangkabau: (1859-1940-an), KPG, Jakarta, h.29, 2013.

[3] Gunawan A, "Indonesia second least literate of 61 nations", The Jakarta Post online, March 12, 2016. http://www.thejakartapost.com/

[4] Murnane R, Sawhill I, Snow C, Literacy Challenges for the Twenty-First Century: Introducing the Issue, Princeton-Brookings, Vol. 22, No.2, h. 3-16, 2012.

[5] Bestor, Arthur, "Dasar-Dasar Pendidikan" dalam Paulo Freire Menggugat Pendidikan, Pustaka Pelajar, Yogyakarta, h. 201, 2009.

\section{DOKUMENTASI KEGIATAN}

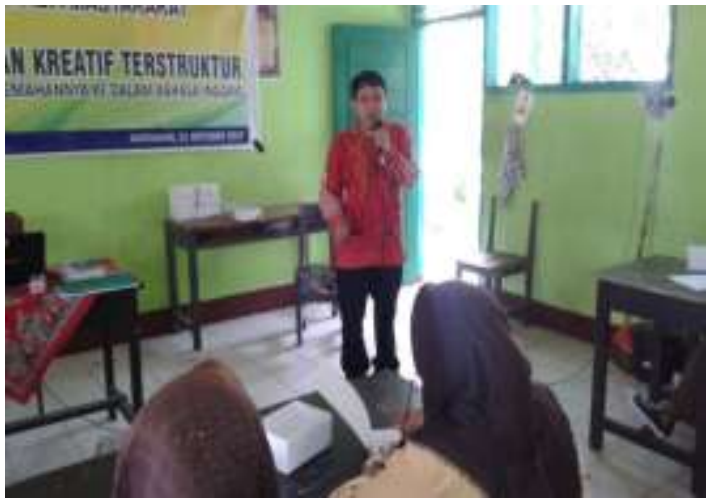

Gambar 1. Penyampaian materi pertama teknik penulisan kreatif terstruktur

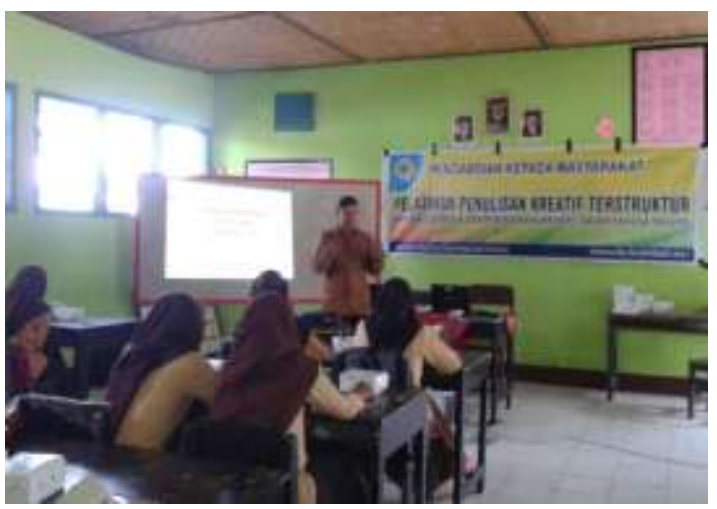

Gambar 2. Penyampaian materi kedua teknik penulisan kreatif terstruktur

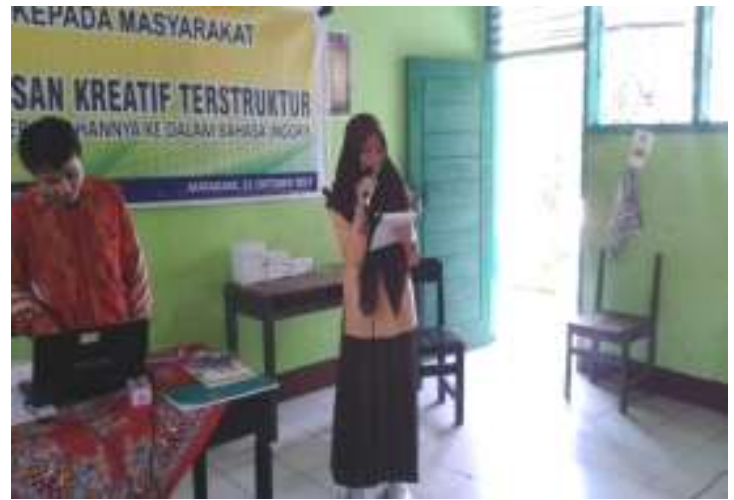

Gambar 3. Pembacaan tulisan terbaik oleh siswa

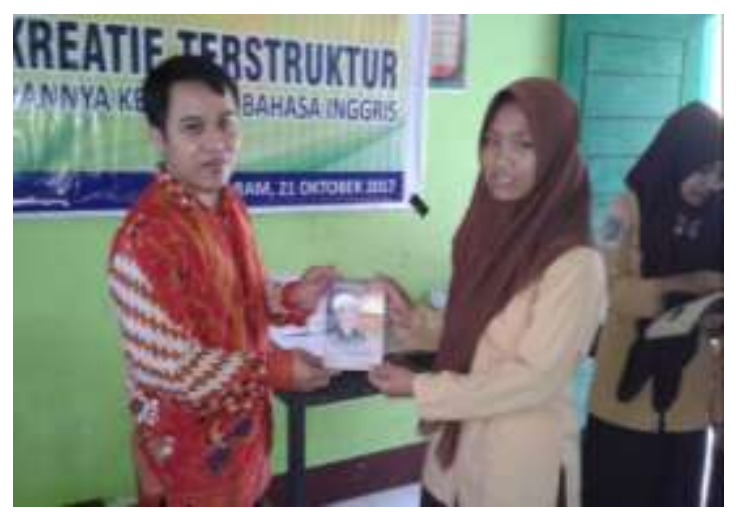

Gambar 4. Penyerahan reward kepada siswa siswa dengan tulisan terbaik 